\title{
Transport properties obtained from magnetotelluric sounding of a granite
}

\author{
David Beamish \\ British Geological Survey \\ West Mains Road \\ Edinburgh EH9 3LA
}

\begin{abstract}
Introduction
The magnetotelluric (MT) technique is a deep exploration method that is undergoing rapid development. Theoretical investigations concerning new exploitations of the electromagnetic wavefield (e.g. Lee et al. 1989) form one leading edge to which field data acquisition and processing are gradually responding. Despite such developments it is probably true that even conventional MT is a poorly understood technique. Case histories using conventional methods and resolutions can, therefore, provide a useful foundation for assessing the role of the technique in present and future exploration programmes.
\end{abstract}

The case study considered here concerns a profile of conventional MT soundings (about $1 \mathrm{~km}$ separation) across a granite outcrop, the Carnmenellis granite, part of a major granite batholith in SW England. Such a granite batholith is, in fact, an unusual target for electromagnetic methods in that granites are normally considered predominantly resistive. The geothermal programme in the UK is presently considering hot dry rock (HDR) exploitation which requires drilling into impermeable rock (e.g. granites possessing high heat flow) and the creation of a reservoir by the stimulation of natural joints and fractures (Parker 1989). Geophysical assessments of rock properties down to depths in excess of $6-8 \mathrm{~km}$ are therefore required when commercially exploitable temperatures, in excess of $200^{\circ} \mathrm{C}$, are to be attained.

A wide-ranging assessment of geological, geochemical and geophysical information has been carried out to evaluate the geothermal resources of SW England. The interior of the batholith, down to $14 \mathrm{~km}$, is seismically featureless (Camborne School of Mines Geothermal Energy Project 1989). The MT survey was in part designed to further investigate the extent to which the Carnmenellis granite could be described as structurally uniform through the critical depth range of possible HDR exploitation.

The case study demonstrates that the MT method, despite the limited range of resistivities encountered across the granite (i.e. it is a relatively homogeneous formation), provides valid details of deep internal structure. The interpretation of such features is particularly challenging because of the granite properties contributing to the bulk resistivity. The main purpose of this paper is to relate the resistivity results to the more familiar rock/ fluid parameters of porosity and permeability. In order to do this, the well-established relationships between hydraulic and electrical conductivities are discussed. The question then addressed is to what extent empirical power-law relationships between transport properties can be applied to surface sounding results.

In order to apply the relationships correctly, the role of fluids and temperature must be taken into account. Actually, if the bulk resistivity results can be corrected to formation temperature, then laboratory-determined relationships can be used to determine both porosity and permeability. Such corrections are routing made in well-log analysis. Since the Carnmenellis granite is currently being studied as an HDR geothermal resource, accurate subsurface temperature predictions are available. This makes the present data set particularly well suited for the estimation of deep transport properties using resistivity soundings.

\section{The MT survey}

Figure 1 shows the MT sounding locations in relation to the outcrop of the Carnmenellis granite. The main E-W profile consisted of 11 sites (solid dots, Fig. 1) at a spacing of approximately $1 \mathrm{~km}$. The audiomagnetotelluric field system collects and analyses seven channels of natural EM fields across four decades of frequency from 100 to $0.01 \mathrm{~Hz}$. Since each sounding represents a volume sounding (at a point) the results may be influenced by three-dimensional structure. A dimensionality assessment of the data suggests that they are influenced by both near-surface static distortions and by the geometrical form of the batholith (Beamish 1990). Static effects in MT are analogous to the effects of near-surface velocity variations on seismic data; hence the use of the term in MT (Orange 1989). Recent schemes to suppress the influence of near-surface resistivity contrasts involve the use of 'continuous' MT profile measurements (Bostick 1986). 


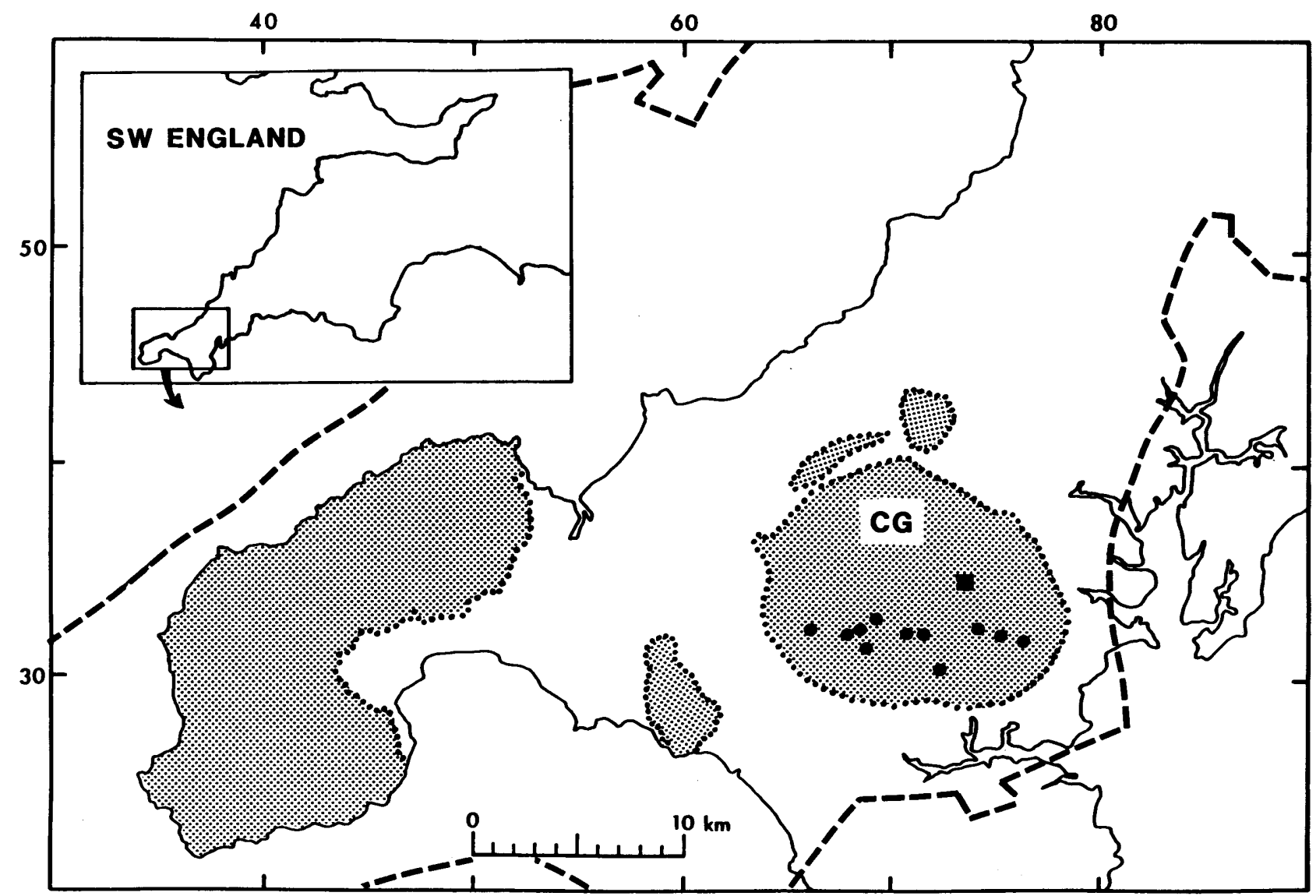

Fig. 1. Survey location map. Granite outcrops are shaded and the 11 sounding sites are the solid dots on the Carnmenellis granite (CG). The dashed line is the $6 \mathrm{~km}$ depth contour of the root Cornubian batholith (data supplied by the Camborne School of Mines Geothermal Energy Project). HDR test site at Rosemanowes quarry is the solid square.

MT sounding curves along a profile can be conveniently plotted as pseudo-sections with decreasing frequency, on a logarithmic scale, representing a form of increasing penetration depth. The tensor nature of the data may require either the selection of an azimuthally dependent sounding curve (e.g. the resistivity/phase curve in a principal horizontal direction) or the reduction of the tensor to a representative scalar and azimuthally invariant curve. The two most common reductions are referred to as the average (or effective) and determinant response curves. A characteristic of near-surface static distortion is that it does not operate on the phase of the MT response. A phase pseudo-section formed from the determinant response will, therefore, provide a semiquantitative and undistorted image of the resistivity structure encountered (e.g. Ranganayaki 1984). The determinant phase pseudo-section, obtained from the 11 soundings of the E-W profile, is shown in Fig. 2. Approximate penetration depths corresponding to frequencies at decade intervals across the measured bandwidth are $1 \mathrm{~km}(100 \mathrm{~Hz}), 5 \mathrm{~km}(10 \mathrm{~Hz}), 18.5 \mathrm{~km}(1 \mathrm{~Hz})$, $50 \mathrm{~km}(0.1 \mathrm{~Hz})$ and $200 \mathrm{~km}(0.01 \mathrm{~Hz})$. The small amount of phase rotation indicates the limited range of resistivities encountered, and the predominantly horizontal zoning indicates the horizontal continuity of the crustal cross-section across the outcrop.
In order to provide quantitative information from conventional MT data suffering static distortion, some form of spatial averaging is usually required. To ensure the complete suppression of static distortion in the present study, the original data set was reduced to a single, granite-average tensor constructed using the 11 soundings on the outcrop (Beamish 1990). The graniteaverage tensor was found to retain a characteristic anisotropy which was investigated by forward twodimensional (2D) modelling of the geometrical form of the batholith. It was established that the observed anistropy could be directly attributed to the $2 \mathrm{D}$ influence of the spatial form of the granite as defined by regional gravity models. Using the 2D model results as control it was also established that the determinant response (obtained from the granite-average tensor) could be used for accurate assessments of the vertical resistivity profile of the granite (Beamish 1990).

The determinant response is obtained as an average from all soundings on the outcrop and represents a spatially and azimuthally averaged resistivity sounding of the regional properties of the Carnmenellis granite. When interpreting the vertical resistivity profile (and subsequently those of porosity and permeability) it should be noted that the results will refer to granite-average properties. Such properties are best understood in 


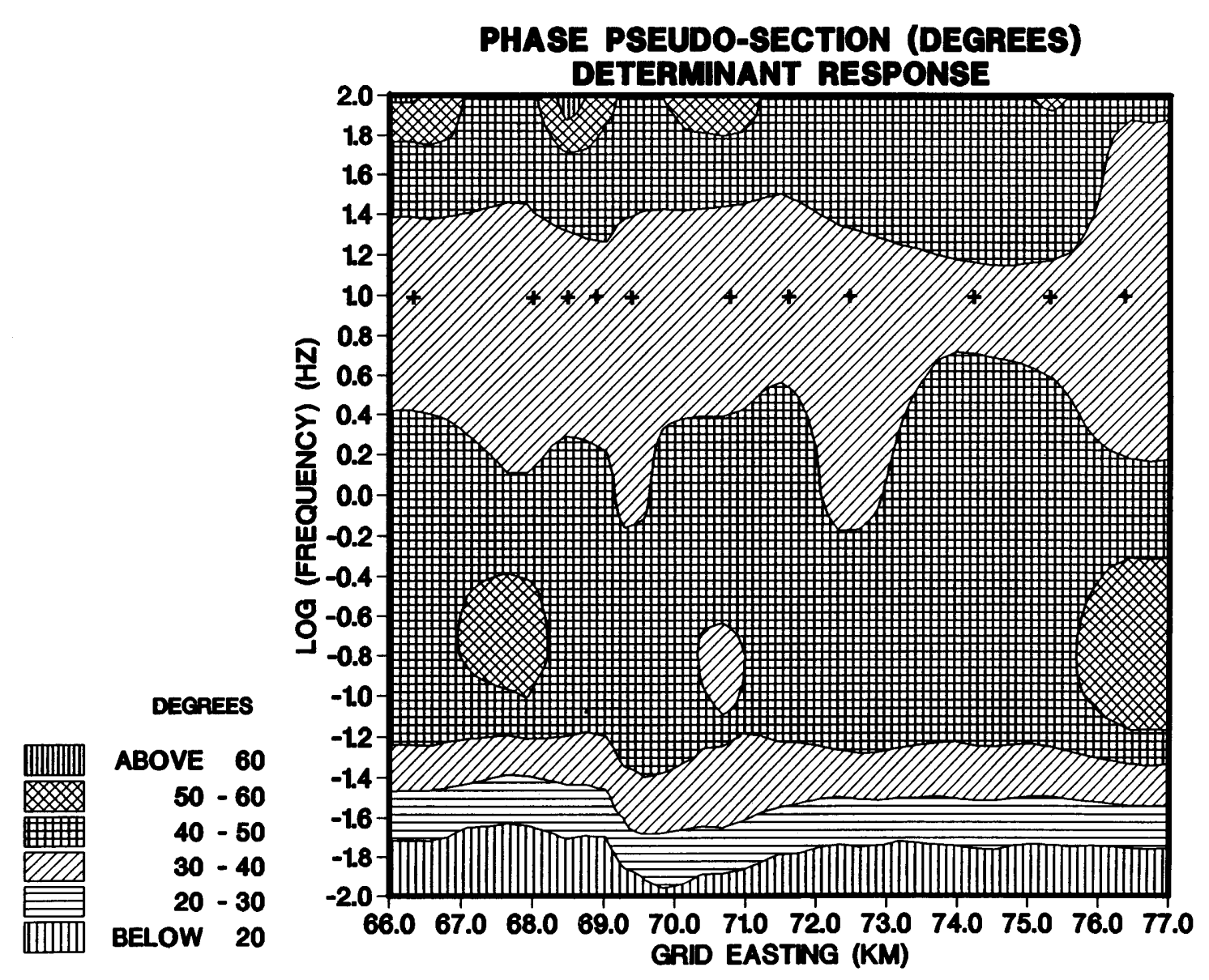

Fig. 2. Determinant phase sounding data displayed as an E-W pseudo-section. The frequency axis covers four decades of sounding bandwidth on a logarithmic (base 10) scale. Phase is contoured on a linear scale at intervals of 10 degrees. Sounding locations are indicated by the horizontal sequence of crosses.

terms of those physical mechanisms which operate in a horizontally continuous manner within the granite. Although spatially localized variations in rock/fluid properties could occur, they are not apparent in the phase pseudo-section of Fig. 2.

\section{The vertical resistivity profile}

When vertical geoelectric structure is to be assessed it is important to realize that there exist a number of distinct interpretation spaces which can be accommodated by one-dimensional (1D) inverse theory. 1D inverse procedures exist for models in which the profile comprises delta functions in conductance (Parker 1983) or, at the opposite extreme, inverse models which are arbitrarily smooth can be generated (Constable et al. 1987). Theory alone shows no preferences, other than those based on misfit criteria, for a particular model type. When assessing an appropriate choice of model, however, reference can be made to other geophysical investigations. The most telling reference (in terms of degree and density of discontinuities encountered across a section) is that available from seismic reflection profiling. No internal structures have been imaged by seismic reflection profiles crossing the batholith (Camborne School of Mines Geothermal Energy Project 1989). From this perspective alone, smooth geolectric models possessing continuous first derivatives are to be preferred.

The results of two inversion schemes that treat the vertical profile as a stack of discrete layers are shown in Fig. 3a. The inversions have been applied to an initial uniform model consisting of three layers and the results shown represent minimum-norm models. The solutions (thin solid and dashed lines) obtained from the two inversion schemes are identical. The resulting model of the granite is simple and comprises a non-uniform upper crustal profile and a granite base. When allowance is made for residual 2D influences, the granite base is estimated to be at a depth of $14 \mathrm{~km}$ (Beamish 1990).

The 1D inversion procedure, discussed above, is a familiar geophysical scheme in that it adopts a "layercake' parameterization of structure. A granite batholith can be viewed as a single lithologic formation and discontinuous behaviour of physical rock properties may be entirely inappropriate (except perhaps at the granite base). This fact, together with the lack of any internal features from the reflection profiles, suggests that solutions involving smooth behaviour will provide a more 


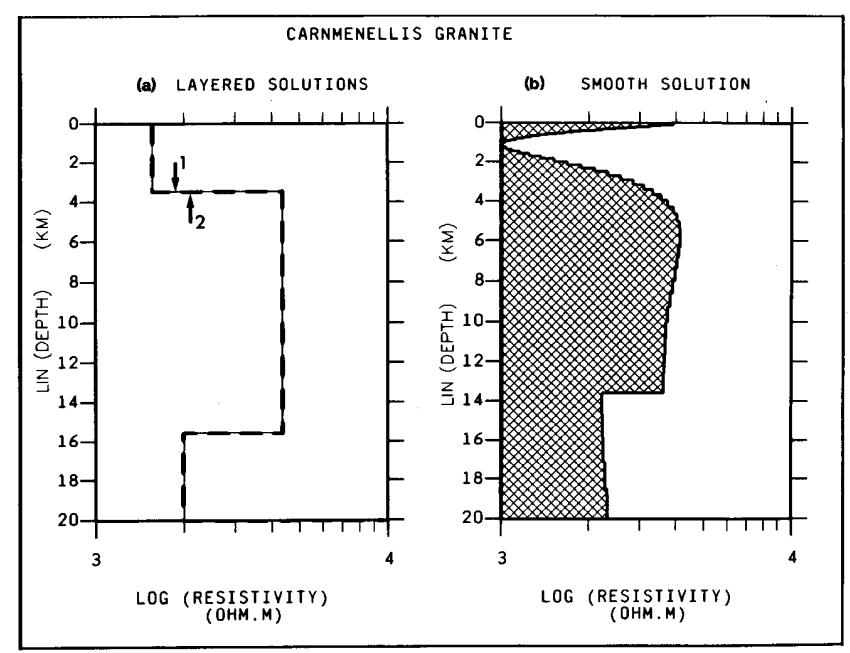

Fig. 3. 1-D inversion results with resistivity on a logarithmic (base 10) scale plotted as a function of depth. (a) Layered solutions from two inversion schemes. Solid thin line (1) is that due to Jupp and Vozoff (1975) and dashed line (2) is that due to Fischer and Le Quang (1981). (b) Equivalent smooth solution as discussed in the text.

realistic parameterization of the internal structure of the granite.

Methods of 1D inversion which find a solution that has the smallest possible roughness (the converse of smoothness) are discussed by Whittall and Oldenburg (1986) and by Constable et al. (1987). The algorithm used for generating smooth vertical profiles is the Occam inversion presented by Constable et al. (1987). Rather than fitting the data as well as possible (which maximizes interface-type behaviour), the smoothest model which fits the data at a prescribed tolerance is sought. Such a model has been constructed.

The solution obtained allows for discontinuous behaviour at the granite base (an a priori constraint of the inversion as suggested by the layered solutions) and is shown in Fig. 3b. It can be seen that the smooth inversion of the survey data produces an upper crustal profile that is a continuous average through the single interface model of Fig. 3a. The smooth model provides a minimum in the resistivity profile at just over $1 \mathrm{~km}$ and a maximum in the depth interval from 5.6 to $6.8 \mathrm{~km}$. The resistivity is then approximately constant down to the granite base.

In order to provide a valid interpretation of the resistivity profile in Fig. 3b, an understanding of the physical mechanisms that influence resistivity variations in 'homogeneous' batholiths is required. The two main mechanisms that will modify resistivity profiles with depth are temperature and pressure. Despite the high geothermal gradient $\left(35^{\circ} \mathrm{C} \mathrm{km}{ }^{-1}\right)$, the anticipated decrease of resistivity with depth does not take place. The vertical results appear, therefore, to have monitored the response of the granite to increasing applied pressure. A realistic model for the resistivity 'structure' within a granite batholith comprises an intact and resistive rock matrix containing voids (ranging in scale from joints to pores) which are saturated with interstitial fluids. Both the flow of fluid (governed by the permeability of the rock) and the flow of electric current (governed by the resistivity of the rock) are then principally controlled by the geometry of the voids and the nature of the fluid content. In such circumstances the internal structure of the granite may be better described in terms of porosity and permeability rather than by the resistivity values per se.

\section{Background to transport properties}

It has long been recognized that the hydraulic (fluid flow) and electrical conductivities of rock should be related since there is an analogy between the differential (diffusion) equations describing each process (e.g. Walsh and Brace 1984). The volume flow rate $\mathbf{Q}$ under a pressure gradient $\nabla p$ is governed by Darcy's law

$$
\mathbf{Q}=-A\left(\kappa \rho_{\mathrm{D}} g / \mu\right) \nabla p
$$

where $A$ is the cross-sectional area, $\kappa$ is the permeability, $\rho_{D}$ is the mass density, $g$ is the acceleration due to gravity, and $\mu$ is fluid viscosity. Likewise, for a permeable material, the conduction of electric current is governed by Ohm's law

$$
\mathbf{J}=-\left(1 / F \rho_{\mathrm{f}}\right) \nabla \mathrm{V}
$$

where $\mathbf{J}$ is the current density and $\nabla \mathrm{V}$ is the potential gradient. In order to introduce fluid properties, the formation factor, $F$, has been defined as the ratio of the bulk resistivity, $\rho$, of the rock over the resistivity of the pore fluid, $\rho_{\mathrm{f}}$ :

$$
F=\rho / \rho_{\mathrm{f}}
$$

The porosity of a material is defined as the ratio of the volume of void space to the total volume. According to Norton and Knapp (1977) the total porosity, $\Phi_{\mathrm{T}}$, may be represented as

$$
\Phi_{\mathrm{T}}=\Phi_{\mathrm{F}}+\Phi_{\mathrm{D}}+\Phi_{\mathrm{R}}
$$

where $\Phi_{\mathrm{F}}$ is the effective flow porosity and represents those pores through which the dominant mode of fluid and aqueous transport is by fluid flow; $\Phi_{\mathrm{D}}$ is the diffusion porosity and represents those pores through which the dominant mode of transport is by diffusion through the aqueous phase; and $\Phi_{\mathrm{R}}$ accounts for residual pores not accounted for by $\Phi_{\mathrm{F}}$ and $\Phi_{\mathrm{D}}$. Therefore, the effective porosity, $\Phi_{\mathrm{E}}$, being the porosity of all interconnected pores, can be taken as

$$
\Phi_{\mathrm{E}}=\Phi_{\mathrm{F}}+\Phi_{\mathrm{D}}
$$

There are two methods of transport parameter estimation. Empirical relationships can be used to estimate a particular material property given measurements of another. The practice is routine in well-log analysis. Conventionally, in core analysis for hydrocarbons, the logarithm of the permeability is plotted against the logarithm of the formation factor. If an adequately linear relationship is observed, downhole electrical 
resistivity measurements can be used to estimate permeability (Archie 1942; Wyllie and Rose 1950). Although largely developed for sedimentary formations, this type of empirical approach has also been extended to permeability determination in crystalline rocks (e.g. Katsube and Hume 1987).

Numerous attempts have also been made to model the transport behaviour of the microscopic geometry of voids in order to predict permeability and formation factor. Such models incorporate parameters such as hydraulic radius (ratio of the void volume to its wetted area) and tortuosity (ratio of the equivalent channel length to the sample length). Recent model simulations, which allow for the effects of rough surfaces in contact, continue to suggest that one can relate the microscopic physics of the transport properties to the macroscopic behaviour described by Darcy's and Ohm's laws (Brown 1989). The present study makes use of surface sounding data to predict the subsurface transport properties by applying the empirical, power-law relationships conventionally used in well logging.

\section{Fluids and temperatures}

Equation (3) provides the important link between the measured bulk resistivity and the formation factor, which can be further related to porosity and permeability. In order to obtain valid estimates of formation factor, a realistic assessment of fluid resistivity and its variation with temperature (i.e. depth) must be made.

Rock-water interactions in the granite have been considered by Edmunds et al. (1988). The granite contains high salinity (up to $30 \mathrm{~g} \mathrm{l}^{-1}$ ) groundwaters that are considered to persist to depths of at least 6 to $7 \mathrm{~km}$ (Edmunds et al. 1988). By all accounts the granite matrix must be viewed as a fully saturated material through the range of effective porosities implied by (5).

In order to determine formation factor as a function of depth, using (3), the influence of temperature must be taken into account. The experimental results of Lee $e t$ al. (1983) confirm the model for the temperature dependence of electrical resistivity in saturated granites is represented by the thermal dependence of the electrical resistivity of the saturating fluid. If the pore fluid has a salinity close to sea water, as suggested above, then the fluid resistivity, $\rho_{\mathrm{f}}$, in ohm $\mathrm{m}$, will depend on temperature as

$$
\rho_{\mathrm{f}}=(3+T / 10)^{-1}
$$

where $T$ is temperature in ${ }^{\circ} \mathrm{C}$ (Nobes et al. 1986). The predicted subsurface temperature profile, calculated from the 1D heat transfer equation (Camborne School of Mines. Geothermal Energy Project 1989), is shown by the discrete symbols in Fig. 4. The applicability of (6) extends to the temperature interval between 300 and $400^{\circ} \mathrm{C}$ and therefore the equation is applied here to a maximum

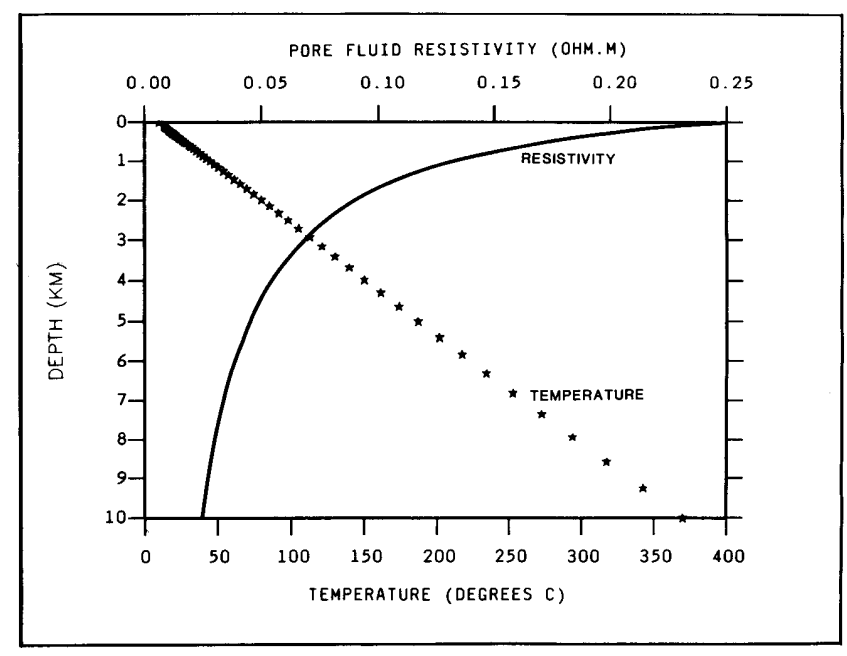

Fig. 4. Variation of temperature (solid symbols and lower axis) and pore fluid resistivity (solid curve and upper axis) with depth.

depth of $10 \mathrm{~km}$ which corresponds to a temperature of $370^{\circ} \mathrm{C}$. It is also assumed, as Edmunds et al. (1988) suggest, that there is no substantial change in fluid salinity with depth. The calculated variation of $\rho_{\mathrm{f}}$ with depth is shown as the continuous curve in Fig. 4. The result indicates a factor of 10 decrease over the first $10 \mathrm{~km}$ of the crustal section. In order to estimate formation factor, the resistivities obtained from the MT data are combined with the estimated variation of $\rho_{\mathrm{f}}$ (shown in Fig. 4) using (3). These results form the basis for the estimation of porosity and permeability as discussed below.

\section{Porosity estimation}

For the case of rocks of bulk resistivity $\rho$, containing a pore fluid of resistivity $\rho_{\mathrm{f}}$, Archie's (1942) law provides a simple power-law relationship between formation factor and effective porosity, $\Phi_{\mathrm{E}}$ :

$$
F=\rho / \rho_{\mathrm{f}}=a \Phi_{\mathrm{E}}^{-m}
$$

where $a$ and $m$ are empirical coefficients. An additional multiplicative term may be included to allow for the degree of fluid saturation, but here complete saturation is assumed. The value for the parameter $a$ varies from slightly less than unity for rocks with intergranular porosity to slightly more than unity for rocks with joint porosity (Keller and Frishknecht 1966). A value of unity has been adopted here. The value of the exponent $m$ is important for correct application. Brace and Orange (1968) have demonstrated an $m=2$ dependence for a wide range of low-porosity, brine-saturated crystalline rocks. Subsequent experiments using varieties of granite rock types (e.g. Lee et al. 1983) all confirm an $m=2$ dependence, and this value has therefore been adopted.

The application of (7) to determine porosity is undertaken using the estimated results for formation factor. The estimated porosity as a function of depth is shown as the inner infilled profile in Fig. 5. It should be noted that since temperature dependence has been incorporated 


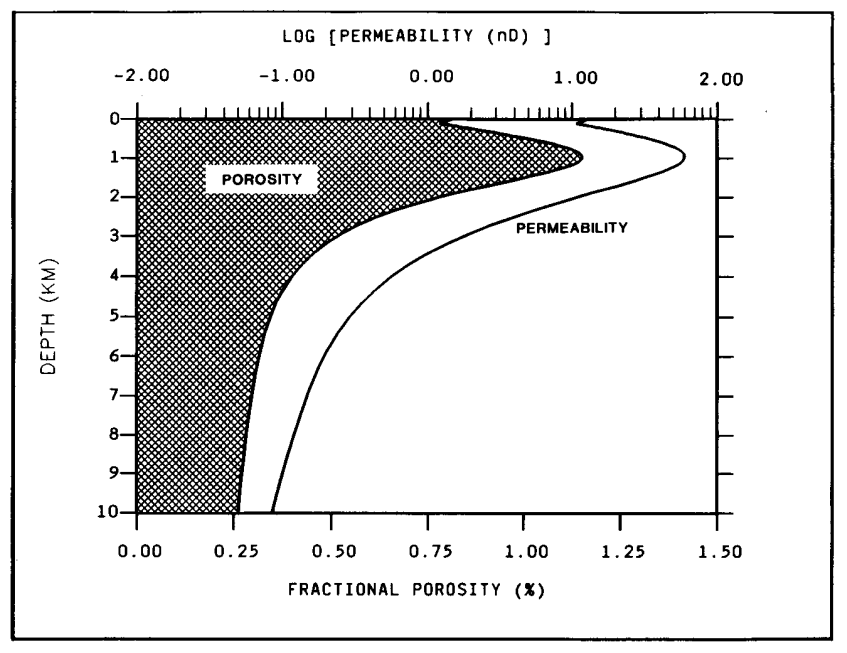

Fig. 5. Variation of porosity (inner infilled profile and lower axis) and permeability (outer solid profile and upper axis) with depth. The fractional porosity is plotted on a linear scale in $\%$ and permeability on a logarithmic (base 10) scale in nanodarcies.

into the estimates of formation factor, the depth dependence of porosity will primarily monitor the response of the granite to increasing pressure with depth.

When attempting to interpret porosity determined from bulk resistivity it should be remembered that all types and scales of void are incorporated into the estimate of effective porosity. Porosity values in the upper 2 $\mathrm{km}$ are consistent with laboratory measurements on other UK granites. Porosities greater than $1 \%$ are confined to the depth interval from 0.5 to $1.5 \mathrm{~km}$, and the subsequent decrease in values must reflect the wellestablished laboratory mechanism of void closure due to increasing pressure (e.g. Brace and Orange 1968). The results of Fig. 5 indicate the onset of fracture/joint closure at a depth of around $1 \mathrm{~km}$. The highly deviatoric horizontal stress field in the granite is estimated to reach about $160 \mathrm{MPa}$ in the maximum direction and $70 \mathrm{MPa}$ in the minimum direction by a depth of $5 \mathrm{~km}$ (Camborne School of Mines Geothermal Energy Project 1989). Beamish (1990) suggests that the vertical resistivity profile appears consistent with the completion of joint and crack closure by $7 \mathrm{~km}$. If this is correct then the porosity values below $7 \mathrm{~km}(0.3-0.25 \%)$ would represent the residual diffusion porosity of (5).

\section{Permeability estimation}

Archie (1942) also noted an empirical power-law relationship between permeability and formation factor:

$$
k=b F^{-r}
$$

Brace et al. (1968) confirmed the relationship from measurements of permeability and resistivity at pressures up to $400 \mathrm{MPa}$. Walsh and Brace (1984) present a simple theoretical flow model to show that the exponent $r$ must fall in the range $1 \leq r \leq 3$. The constant $b$ is related to the hydraulic radius. Brace (1977) suggested that in order to determine permeability from deep resistivity measurements, adequate estimates of the hydraulic radius must be available. Although this is theoretically true, it is also possible to obtain empirical estimates of the constant $b$ in the same manner that estimates of the exponent $r$ can be obtained for different formations. Walsh and Brace (1984) summarize a number of determinations of the exponent $r$ in granites, ranging from 1.5 to 2.4 .

To apply (8), the empirical constants $b$ and $r$ should be determined for the formation under investigation. Again, the correct choice of exponent is of prime importance. In the absence of specific determinations of $b$ and $r$ for the Carnmenellis granite, measurements made within the Lac du Bonnet granite by Katsube and Hume (1987) have been adopted. The values obtained by Katsube and Hume (1987) are $b=2.51 \times 10^{-7}$ and $r=$ 2.22 with the permeability being given in $\mathrm{am}^{2}\left(1 \mathrm{am}^{2}=\right.$ $10^{-18} \mathrm{~m}^{2}=1 \mu$ Darcy)

The application of (8) to determine permeability is undertaken using the estimates of formation factor. The variation of permeability, on a logarithmic scale, with depth is shown as the outer solid line in Fig. 5. By comparing the results displayed in Fig. 5 it can be seen that the porosity and permeability provide equivalent information, as would be expected from (7) and (8).

The maximum permeability of $60 \mathrm{nD}$ occurs at a depth of about $1 \mathrm{~km}$. This maximum appears consistent with the near-surface hydrogeological model of the granite described by Burgess et al. (1982). According to the model, a saline circulation system extends to a depth of 1.1-1.2 km, implying the existence of hydraulically significant fractures to the same depth.

The dependence of fluid permeability of Westerly granite on effective confining pressure was studied by Brace et al. (1968) for pressures in the range 0 to 400 $\mathrm{MPa}$. The permeability at zero pressure was estimated to be about $500 \mathrm{nD}$, and clearly the present estimates fall well below this value. In situ measurements on certain granites do have permeabilities comparable with the present estimates (Brace 1984), but it should be noted that scale is particularly important in permeability determination and the results of Fig. 5 are a granite-average property. The permeability estimates of Brace et al. (1968) decreased markedly with pressure up to about $100 \mathrm{MPa}$, reflecting the closure of high aspect ratio microcracks. A less rapid decrease occurred at pressures above about $200 \mathrm{MPa}$ with the permeability measured at $400 \mathrm{MPa}$ being 3-4 $\mathrm{nD}$. The lower permeabilities indicated by the present determinations may be genuine or due to an inappropriate choice of empirical constants.

\section{Conclusions}

This case study across a granite demonstrates that the MT method provides details of deep internal structure 
not imaged by other geophysical techniques.

It has been suggested that when 'exact' $1 \mathrm{D}$ inverse algorithms are applied, some consideration should be given to the most appropriate interpretational space (e.g. interface, layered or smooth solutions). Such non-uniqueness is inherent in most geophysical methodologies but it is not always stated explicitly or investigated. The vertical profile results presented here aim to demonstrate that a resistivity profile can provide valid estimates of those rock/fluid properties which are 'continuous'.

The main purpose of the present study has been to examine the subsurface structure of the granite by applying techniques that are already established in well-log analysis to the resistivity sounding data. The results suggest that if adequate laboratory-derived relationships exist, then resistivity values can be used to provide adequate estimates of porosity and permeability for the formation under study. In order to provide such estimates, the role of fluids must be assessed over the depth interval of the investigation and a realistic temperature profile must be available. When these conditions are met, fluid resistivity values can be temperature-corrected using (3) and a valid formation factor can be derived using (6). The formation factor provides the link between the measured electrical resistivity and the porosity and permeability.

The effective porosity (and permeability) derived from resistivity profiles cannot distinguish between flow and diffusion porosity. All scales of void are incorporated into the estimates. However, a useful property of the porosity/depth profiles derived by the method described is that, in contrast to bulk resistivity, the profiles are temperature-corrected and will provide information on the response of the formation to the pressure/stress field. The vertical profiles of transport properties (Fig. 5) appear to be interpretable in terms of the progressive closure of the near-surface fracture system, followed by that of the joint system. The onset depth of fracture/ joint closure in the Carnmenellis granite appears to be about $1 \mathrm{~km}$.

Due to the power-law relationships used, there exists a mapping equivalence between porosity and (the logarithm of) permeability. Near-surface porosity estimates are consistent with data available from other UK granites but permeabilities appear somewhat low in relation to laboratory estimates. It is not known whether this is genuine or due to an inappropriate choice of empirical constants.

\section{Acknowledgements}

My thanks go to the staff of Camborne School of Mines, Geothermal Energy Project, at Rosemanowes Quarry, who provided facilities and advice. My thanks also to the referee who provided helpful advice on an earlier version of this paper. The original data were collected under a contract from the Camborne School of Mines,
Geothermal Energy Project as part of the Department of Energy's Renewable Energy research and development programme, managed by the Energy Technology Support Unit (ETSU). The views and judgements expressed in this paper are those of the author and do not necessarily reflect those of ETSU or the Department of Energy. This report is published with the approval of the Director, British Geological Survey (NERC).

\section{References}

ARCHIE G.E. 1942. The electrical resistivity log as an aid in determining some reservoir characteristics. Transactions AIME 146, 5467.

Beamish, D. 1990. A deep geoelectric survey of the Carnmenellis granite. Geophysical Journal International 103, in press

Bostick, F.X. 1986. Electromagnetic array profiling. 56th SEG Meeting, Houston, Expanded Abstracts, 60-61.

Brace, W.F. 1977. Permeability from resistivity and pore shape. Journal of Geophysical Research 82, 3343-3349.

BRACE, W.F. 1984. Permeability of crystalline rocks: new in situ measurements. Journal of Geophysical Research 89, 4327-4330.

Brace, W.F. and Orange, A.S. 1968. Further studies of the effects of pressure on electrical resistivity of rocks. Journal of Geophysical Research 73, 5407-5420.

Brace, W.F., Walsh, J.B. and Frangos, W.T. 1968. Permeability of granite under high pressure. Journal of Geophysical Research 73, 2225-2236.

Brown, S.R. 1989. Transport of fluid and electric current through a single fracture. Journal of Geophysical Research 94, 9429-9438.

Burgess, W.G., Edmunds, W.M., Andrews, J.N., Kay, R.L.F. and LEE, D.J. 1982. The origin and circulation of groundwater in the Carnmenellis granite: the hydrogeochemical evidence. Investigation of the geothermal potential of the UK (1982), 82pp. Report, British Geological Survey.

Camborne School of Mines Geothermal Energy Project 1989. 2C-7 Resource evaluation: overview. ETSU Report No. G137-P14A, 71 pp.

Constable, S.C., Parker, R.L. and Constable, C.G. 1987. Occam's inversion: a practical algorithm for generating smooth models from electromagnetic sounding data. Geophysics 52, 289-300.

Edmunds, W.M., Andrews, J.N., Bromley, A.V., Kay, R.L.F., Milodowski, A., Savage, D. and Thomas, L.J. 1988. Granitewater interactions in relation to Hot Dry Rock geothermal development. Investigation of the geothermal potential of the UK (1988), 116 pp. Report, British Geological Survey.

FISCHER, G. and LE QUANG, B.V. 1981. Topography and minimisation of the standard deviation in one-dimensional magnetotelluric modelling. Geophysical Journal of the Royal Astronomical Society $67,257-278$.

JuPP, D.L.B. and Vozoff, K. 1975. Stable iterative methods for the inversion of geophysical data. Geophysical Journal of the Royal Astronomical Society 42, 957-976.

Katsube, T.J. and Hume, J.P. 1987. Permeability determination in crystalline rocks by standard geophysical logs. Geophysics 52, 342-352.

Keller, G.V. and Frishrnecht, F.C. 1966. Electrical methods of geophysical prospecting. Pergamon, Oxford.

LEE, C.D., Vine, F.J. and Ross, R.G. 1983. Electrical conductivity models for the continental crust based on laboratory measurements on high-grade metamorphic rocks. Geophysical Journal of the Royal Astronomical Society 72, 353-371.

LEE, K.H., Liu, G. and Morrison, H.F. 1989. A new approach to modeling the electromagnetic response of conductive media. Geophysics 54, 1180-1192. 
Nobes, D.C., Villinger, H., Davis, E.E. and Law, L.K. 1986. Estimation of marine sediment bulk physical properties at depth from seafloor geophysical measurements. Journal of Geophysical Research 91. 14033-14043.

NorTON, D. and KNAPP, R. 1977. Transport phenomena in hydrothermal systems: the nature of rock porosity. American Journal of Science 277, 913-936.

ORANGE, A.S. 1989. Magnetotelluric exploration for hydrocarbons. Proceedings of the IEEE 77, 287-317.

PARKER, R. 1989. The Camborne School of Mines hot dry rock geothermal energy project. Scientific Drilling 1, 34-41.

PARKER, R.L. 1983. The magnetotelluric inverse problem. Geophysical Surveys 6, 5-25.
RANGANAYAKI, R.P. 1984. An interpretive analysis of magnetotelluric data. Geophysics 49, 1730-1748.

WALSH, J.B. and BRACE, W.F. 1984. The effect of pressure on porosity and the transport properties of rocks. Journal of Geophysical Research 89, 9425-9431.

Whittall, K.P. and Oldenburg, D.W. 1986. Inversion of magnetotelluric data using a practical inverse scattering formulation. Geophysics 51, 383-395.

WyLliE, M.R.J. and Rose, W.D. 1950. Some theoretical considerations related to the quantitative evaluation of the physical characteristics of reservoir rock from electrical log data. Transactions AIME 189, 105-118. 